\title{
Psychological Mindedness and Procrastination among University Students
}

\author{
Priyanka Pathak ${ }^{1}$, Prof. Shobhna Joshi ${ }^{2 *}$
}

\section{ABSTRACT}

This study was conducted to investigate the relationship between psychological mindedness and procrastination among university students and to determine gender differences in psychological mindedness and procrastination. The sample consisted of 200 university students (100 male and 100 female) aged 18 to 25 years from different faculties of Banaras Hindu University, Varanasi. Psychological mindedness scale (PMS) by Conte et al., (1986) and Tuckman procrastination scale by Tuckman (1991) along with personal data sheet were used to assess the level of psychological mindedness and procrastination among university students. Psychological mindedness is the ability to psychological understanding of the self and other's behaviour, thought and feelings. It is openness to new ideas whereas procrastination is known as the irrational tendency of delaying the tasks until an individual experiences discomfort (Solomon \& Rothblum 1984). Results showed that there were no significant gender differences in psychological mindedness and procrastination. Correlational analysis indicated that the psychological mindedness was significantly negatively correlated with the level of procrastination; i.e., the higher the level of psychological mindedness the lower the level of procrastination. Thus, it can be concluded that psychological mindedness play an important role in procrastination among university students. The theoretical and practical implications of these findings are discussed.

\section{Keywords: Psychological Mindedness, Procrastination, University Students}

Traditionally, educational institutions have viewed intelligence to be the best predictor of achievement in academic settings. According to O’Connor \& Paunonen (2007), the relationship between academic achievement and intelligence is weaker than expected, especially in a higher education environment. In addition, Diseth (2002) found a lack of relationship between intelligence and academic achievement. Academic achievement may thus depend on more than

\footnotetext{
${ }^{1}$ Research scholar, Dept. of Psychology, BHU, India

${ }^{2}$ Professor, Dept. of Psychology, BHU, India

*Responding Author
}

Received: December 29, 2016; Revision Received: January 19, 2017; Accepted: January 30, 2017

(C) 2017 Pathak P, Joshi S; licensee IJIP. This is an Open Access Research distributed under the terms of the Creative Commons Attribution License (www.creativecommons.org/licenses/by/2.0), which permits unrestricted use, distribution, and reproduction in any Medium, provided the original work is properly cited. 


\section{Psychological Mindedness and Procrastination among University Students}

just intelligence as students with high cognitive abilities are often outperformed by students with lower cognitive abilities. Kapp (2000) mentions that "as work becomes more complex and collaborative, emotional competence will distinguish those who flourish from those who falter". As an important part of the psychology of emotion and inter and intrapersonal awareness, psychological mindedness can be used to measure emotional competence. According to Beitel et al., (2009) psychological mindedness has wide-ranging appeal and utility as a result of it being not only a basic psychological construct but also perhaps the most important psychological strength.

According to Farber (1985), the history of psychological mindedness dates back to Murray's (1938) concept of "intraception" (a disposition toward emphasizing the psychological aspects of persons or events) and before that to Jung's (1922) concept of "introversion" and William James' (1907) concept of "tender minded."

The term psychological mindedness (PM) arose from psychodynamic thinking (Appelbaum, 1973; Taylor et al, 1989), and for a long time, its use confined to psycho-dynamically oriented psychotherapy practice, in which the patient's level of psychological mindedness was viewed as an important prerequisite for insight-oriented therapy to be successful (Taylor et al., 1989). Psychological mindedness represents an abstract process, not directly observable. Words including insightfulness, reflectiveness, self-appraisal, self-awareness, and introspection have been used synonymously with psychological mindedness (Applebaum, 1973). Some important definitions of psychological mindedness are given below:

Tolar and Rezinikoff (1960) defined "psychological mindedness as an ability to comprehend the causative factors that underlie or determine behaviours and general attitudes”. Appelbaum (1973) defines psychological mindedness as "a person's ability to see relationships among thoughts, feelings, and actions, with the goal of learning the meanings and causes of experiences and behaviour". The four dimensions, thought of explaining psychological mindedness to underlie this capability includes: (a) cognitive abilities and intuitive talents, (b) a curiosity and genuine interest in human beings such that an individual is intrigued by the way that the mind works, is capable of concern for the self and is similarly able "to allow affects their rightful place," (c) for purposes of treatment, a self-directedness that characterizes a person's psychological thinking and (d) a present and prospective ability on the part of the individual "to put his capacities for psychological thinking at the service of the psychoanalytic process” (Appelbaum, 1973).

Conte et al., (1996) has conceptualized psychological mindedness as an attribute of an individual that presupposes a degree of access to one's feelings, a willingness to try to understand oneself and others, a belief in the benefit of discussing one's problems, and interest in the meaning and motivation of one's own and others thoughts, feelings and behaviour and capacity for change. 


\section{Psychological Mindedness and Procrastination among University Students}

In a study Nyclíček \& Denollet (2009) stated that psychological mindedness is a personal (individual) characteristic that reflects not only interest but also the ability and can be changed by meaningful external sources. Thus psychological mindedness includes cognitive, affective and motivational components and may be viewed as a characteristic, an interest and an ability, with a focus on both the individual and others.

College life is an excellent context in which students can completed their tasks at any time because they have long term deadlines. Students, at all level in college are always concerned with increasing procrastination in their academic task. This means procrastination is a chronic problem in college life and continues throughout the life.

Procrastination is not a new phenomenon. William James recognized the procrastination 120 years ago and Steel (2007) traces procrastination references back to 800 B.C. Contemporary psychologists are increasingly interested in conducting research that explains procrastination but in spite of growing research attention, "much has yet to be learned about the causes of procrastination" (Steel, 2007) and procrastination remains "one of the least understood human miseries" (Ferrari, 1994). The empirical and theoretical foundations of procrastination research are less well established than those of other psychological constructs, even though procrastination is common and can lead to stress and illness ( Dewitte \& Schouwenburg, 2002; Fritzsche, Young \& Hickson, 2003). The study of procrastination and its consequences has received increased empirical attention within the field of psychology over the past several decades. In general, procrastination has long been identified as a negative behaviour and procrastinators perceive this behaviour as a problem that they wanted to reduce because of its serious negative outcomes (Ferrari, 1991; Solomon \& Rothblum, 1984).

The term procrastination is derived from the Latin word "pro," which means forward, and "crastinus," which means tomorrow (Mish, 1994). It means to put off, delay, prolong, defer, stall or postpone performing a task. Procrastination is a common behaviour in contemporary societies. Solomon and Rothblum (1984) defined procrastination as "the act of needlessly delaying tasks to the point of experiencing subjective discomfort." It is a tendency to put off, avoid or delay activities. It has also been characterized as "delaying task completion to the point of experiencing subjective discomfort" by (Ferrari, 1992) and "intentional delay of an intended course of action” by (Klassen, Krawchuk \& Rajani, 2008).

Procrastination affects almost every single individual at some point in his or her life. Some researchers have even stated that nearly one-quarter of the adult population is affected by procrastination (Ferrari, 1994). Research on procrastination also shows that procrastination often results when a task seems difficult unpleasant or overpowering (Akinsola, Tella and Tella, 2007). Hammer and Ferrari (2002) found as many as $20 \%$ of adults experience chronic procrastination for everyday tasks, while the rate for problematic academic procrastination among 


\section{Psychological Mindedness and Procrastination among University Students}

undergraduates is estimated to be at least 70-95\% (Ellis \& Knaus, 1977; Steel, 2007), with estimates of chronic or severe procrastination among undergraduates between 20\% and 30\% (Ferrari, Johnson \& McCown, 1995; Solomon \& Rothblum, 1984).

A thorough review of literature related to psychological mindedness was done and it was found that very limited studies have been conducted to see the effect of psychological mindedness on academic achievement but not procrastination yet. Psychological mindedness plays an important role in growing the understanding of self. In recent years researchers have tried to understand its role in academic setting and search out how it is related to academic performance of a student. Among existing few studies pertaining to psychological mindedness a recent study of Beets, Nienaber, \& Botha (2010) was found to be significant during review. In their study Beets, Nienaber \& Botha (2010) determined the relationship between psychological mindedness and academic achievement and their findings show that psychological mindedness is directly proportional to academic achievement. In early recent study Debra (2014) demonstrated that psychological mindedness includes a general attentiveness plus an interest in psychological conceptualization, mindfulness and may be necessary precondition for psychological thinking.

\section{Background of the study}

Procrastination appears to make university students postpone or delaying their different tasks related to academic and other settings. Students may become frustrate and disturbed that affects largely on their learning and achievement. These issues need to be resolved appropriately. No such study appeared conducted in Indian Context. Therefore, it was reasonable to conduct a study to explore the issue related variables. According to Fagan \& Squitiera (2002), academically strong students may possess characteristics that may be associated with psychological mindedness. There might thus be a relationship between psychological mindedness and academic achievement. The correlation between psychological mindedness and procrastination as well as the differences in gender in relation to both psychological mindedness and procrastination was investigated. This study is significant and important, as no previous research was found that investigated the relationship between psychological mindedness, procrastination and gender. Increased knowledge regarding the factors influencing academic procrastination may be beneficial in pointing students in the right direction, identifying students who need assistance, and helping them as needed to enable them to achieve academic success. Most clinicians intuitively understand the meaning and value of the psychological mindedness in psychotherapy purposes yet empirical attention has been relatively scant. Further research is required to explore in this direction.

\footnotetext{
Aims

This study aims to determine first whether there is a relationship between psychological mindedness and procrastination, and secondly whether students' psychological mindedness and procrastination differ on the grounds of gender.
}

(c) The International Journal of Indian Psychology, ISSN 2348-5396 (e)| ISSN: 2349-3429 (p) | 8 


\section{Psychological Mindedness and Procrastination among University Students}

\section{Objectives}

1. To examine the relationship between psychological mindedness and procrastination among university students.

2. To examine the gender differences in psychological mindedness and procrastination among university students.

\section{Hypotheses}

1. There would be negative relationship between psychological mindedness and procrastination among university students.

2. There would be significant gender differences between male and female university students on psychological mindedness and procrastination.

\section{METHODOLOGY}

\section{Design:}

The present study would follow a correlational design in which psychological mindedness would be treated as predictor variable and procrastination would be treated as criterion variable.

\section{Sample}

Total sample of 200 subjects were taken for this study. The sample comprises of 100 male and 100 female university students. The age range of the subjects was between 18 - 25 years. Data was collected from Banaras Hindu University, Varanasi.

\section{Procedure}

Following psychometric devices would be used to study the variables in the present investigation. Scoring would be done according to their respective manuals and scoring keys.

\section{Tools}

- Socio demographic datasheet was prepared by the investigator for collecting information about Name, Age, Sex, and Education, father's education, mother's education and type of family.

Psychological Mindedness Scale (PMS):- Psychological mindedness scale developed by Conte, Plutchik, Jung, Picard, Karasu, \& Lotterman, (1990) was be used to assess psychological mindedness of the subjects. It consists of 45 items in which twenty items are reverse scored. It is a self report measure and includes five factors that is (1) willingness to try to understand oneself and others; (2) openness to new ideas and capacity to change; (3) access to feelings; (4) belief in the benefits of discussing one's problems; and (5) interest in meaning and motivation of own and others' behaviour. The items are presented on a four point scale and range from "strongly agree" to "strongly disagree" with a higher score indicating greater psychological mindedness. The psychological mindedness scale has shown good temporal stability $(r=0.92)$ and internal consistency ( $\alpha-0.80)$.

(c) The International Journal of Indian Psychology, ISSN 2348-5396 (e) | ISSN: 2349-3429 (p) | 9 
Tuckman Procrastination Scale- Tuckman Procrastination Scale developed by Tuckman(1991). It consists of 16 items to measure task avoidance to academic activities. The items are presented on a four point scale with a higher score indicating greater procrastinator. The Tuckman procrastination scale good internal consistency $(\alpha-0.86)$.

\section{RESULTS}

\section{Descriptive data and inter correlation}

The analysis of the table 1 indicated that psychological mindedness is significantly negatively correlated with procrastination $(r=-.37, \mathrm{p}<0.01)$.

Table1. Descriptive statistics and inter-correlations of the variables

\begin{tabular}{|l|l|c|c|}
\hline \multicolumn{1}{|c|}{ Variable } & $\mathbf{1}$ & $\mathbf{2}$ \\
\hline $\mathbf{1 .}$ & Psychological mindedness & 1 & 1 \\
\hline 2. & Procrastination & $-.37 * *$ & 33.75 \\
\hline & Mean & 126.96 & 5.39 \\
\hline & Standard deviation & 10.50 & $16-64$ \\
\hline & Range & $45-180$ & \\
\hline
\end{tabular}

$* * \mathbf{p}<\mathbf{0 . 0 1}$

\section{Gender differences}

The t-ratio was computed to observe the significance of differences of the mean score of psychological mindedness and procrastination between females and males university students. The results presented in table 2 suggest that there is no significant difference in females' and males' scores on psychological mindedness and procrastination.

Table2. Gender differences on psychological mindedness and procrastination

\begin{tabular}{|c|c|c|c|c|c|c|}
\hline \multirow[t]{2}{*}{ S.N. } & \multirow[t]{2}{*}{ Variable } & \multicolumn{2}{|c|}{ Female $(n=100)$} & \multicolumn{2}{|c|}{ Male $(n=100)$} & \multirow[t]{2}{*}{$\mathbf{t}$} \\
\hline & & $\mathbf{M}$ & SD & $\mathbf{M}$ & SD & \\
\hline 1. & $\begin{array}{l}\text { Psychological } \\
\text { mindedness }\end{array}$ & 126.71 & 10.68 & 127.20 & 10.38 & -.329 \\
\hline 2. & Procrastination & 33.77 & 5.48 & 33.72 & 5.34 & 0.65 \\
\hline
\end{tabular}

\section{DISCUSSION}

This study aimed to determine whether there is a relationship between psychological mindedness and procrastination, and whether there are differences in gender variables in relation to both psychological mindedness and procrastination respectively. Psychological mindedness is significantly negatively correlated with procrastination. Students with a high psychological mindedness will probably be, as indicated by Conte et al., (1996) and Nycliček \& Denollet (2009), interested in and understand not only the meaning and motivation behind emotions (affective aspects), thoughts (cognitive aspects) and behaviour (motivational aspects), but also the relationships between them. It means psychological minded people have been shown to 


\section{Psychological Mindedness and Procrastination among University Students}

possess many psychological strengths, such as access to one's feelings, a willingness to try to understand oneself and others, a belief in the benefit of discussing one's problems, and interest in the meaning and motivation of one's own and others thoughts, feelings and behaviour and capacity for change.

As the correlations between psychological mindedness and the procrastination medium nature it can be deducted that psychological mindedness plays a important role in determining the tendency of procrastination and it reduction. It is also found in this study that females and males did not differ on psychological mindedness and procrastination With regard to gender, the results of this study contrast with those of Shill \& Lumley (2002), who found that female students obtained higher scores on psychological mindedness than male students. Results regarding the relationship between gender with psychological mindedness and procrastination are thus mixed and should be explored in future research.

Thus the study makes several contributions. Firstly, it demonstrates that psychological mindedness is associated with procrastination. Secondly, this study was the first to examine the relationships between psychological mindedness and procrastination.

The findings of the present study revealed that there were significant negative correlation between psychological mindedness and procrastination and no significant gender differences were found on psychological mindedness and procrastination. As psychological mindedness is regarded as positive and academic procrastination is negative feature Expectation is proved in this study, a significant relationship was found between psychological mindedness and procrastination. In summary the higher a student's psychological mindedness, the lower his/her procrastination.

\section{LIMITATIONS}

A limitation of this study is that we acknowledge that our sample size was very small. However, participants were university students only; so generalizability is limited. Another is the Psychological Mindedness Scale is a self-report measure of how participants view themselves and not of how others view them.

\section{FURTHER SUGGESTIONS}

It is recommended that further studies on psychological mindedness and procrastination include a questionnaire that captures the participants' different aspects related to mood, and in a larger and more diversified sample. It is also recommended that the five dimensions of the psychological mindedness scale be analysed separately, as this may give an indication of exactly which factors in the scale correlate the best with procrastination. If this is known, specific attention may be paid to the development of these factors among students who are struggling academically by for example, developing and presenting intervention programmes on 


\section{Psychological Mindedness and Procrastination among University Students}

psychological mindedness. As higher psychological mindedness is associated with better academic achievement, such a programme might not only assist students in developing certain beneficial psychological skills but will also help them to improve on their academic results. Future work could examine the multiple factors that constitute psychological mindedness and procrastination in a larger, gender sample.

\section{Acknowledgments}

The author appreciates all those who participated in the study and helped to facilitate the research process.

\section{Conflict of Interests}

The author declared no conflict of interests.

\section{REFERENCES}

Akinsola, M. K., Tella, A., \& Tella, A. (2007). Correlates of academic procrastination and mathematics achievement of university undergraduate students. Eurasia Journal of Mathematics, Science \& Technology Education, 3(4), 363-370.

Appelbaum, S. A. (1973). Psychological-mindedness: Word, concept and essence. International Journal of Psycho-Analysis, 54, 35-46.

Beets,S., Nienaber, A., \& Botha, K.(2010). Psychological mindedness and academic achievement of psychology students in a higher education environment. Acta Academica, 43(3), 32-56

Beitel, M., Hutz, A., Sheffield, K.M., Gunn, C., Cecero, C. C., \& Barry, D.T. (2009). Do psychologically-minded clients expect more from councelling. Psychology and Psychotherapy: Theory, Research and Practice, 82(4),369-83.

Conte, H. R., Ratto, R., \& Karasu, T. B. (1996). The Psychological Mindedness Scale: Factor structure and relationship to outcome of psychotherapy. Journal of Psychotherapy Research and Practice, 5, 250-259.

Dewitte, S., \& Schouwneburg, H. C. (2002). Procrastination, Temptations, and Incentives: The Struggle between the Present and the Future in Procrastinators and the Punctual. European Journal of Personality, 16, 469-489.

Diseth, A. (2002). The relationship between intelligence, approaches to learning and academic achievement. Scandinavian Journal of Educational Research, 46(2), 219-30.

Ellis, A., \& Knaus, W. J. (1977). Overcoming Procrastination. NY: New American Library, Signet Books

Fagan, R., \& Squitiera, P. (2002). The relationship between personality characteristics and academic success in Law School. Evaluation and Research in Education,16(2), 95-103.

Farber, B. A. (1985). The genesis, development and implications of psychological-mindedness in psychotherapists. Psychotherapy, 22(2), 170-177.

Ferrari, J. R. (1991a). Procrastination and project creation: Choosing easy, nondiagnostic items to avoid self-relevant information. Journal of Social Behaviour and Personality, 6, 619-628.

Ferrari, J. R. (1992). Procrastination in the workplace: Attributions for failure among individuals with similar behavioral tendencies. Personality and Individual Differences, 13(3), 315-319. 


\section{Psychological Mindedness and Procrastination among University Students}

Ferrari, J. R. (1994). Dysfunctional procrastination and its relationship with self-esteem, interpersonal dependency, and self-defeating behaviors. Personality and Individual Differences, 17(5), 673-679.

Ferrari, J. R., Johnson, J. L., \& McCown, W. G. (1995). Procrastination and task avoidance: Theory, research, and treatment. New York: Plenum Press.

Fritzsche, B. A., Young, B. R., \& Hickson, K. C. (2003). Individual differences in academic procrastination tendency and writing success. Personality and Individual Differences, 35, $1549-1557$.

Hammer, C. A., \& Ferrari, J. R. (2002). Differential incidence of procrastination between blueand white-collar workers. Current Psychology: Developmental, Learning, Personality, Social, 21(4), 333-338.

Jung, C. (1922). Analytic psychology. London: Balliere.

Kapp, C. A. (2000). Emotional intelligence and success in post-graduate studies: a pilot study. SAJHE/SATHO, 14(3), 151-60.

Klassen, R. M., Krawchuk, L. L., \& Rajani, S. (2008). Academic procrastination of undergraduates: low self-efficacy to self-regulate predicts higher levels of procrastination. Contemporary Educational Psychology, 33, 915-931.

Mish, F. (1994). Merriam Webster's Collegiate Dictionary (10th ed.). New York: MerriamWebster.

Murray, H. (1938). Exploration in personality. New York: Oxford University Press.

Nyklíček, I., \& Denollet, J. (2009). Development and evaluation of the balanced index of psychological mindedness (BIPM). Psychological Assessment, 21(1), 32-44.

O’Connor, M. C., \& Paunonen, S.V. (2007). Big five personality predictors of post-secondary academic performance. Personality and Individual Differences, 43, 971-90.

Shill, M.A., \& Lumley, M.A. (2002). The Psychological Mindedness Scale: Factor structure, convergent validity and gender in a non-psychiatric sample. Psychology and Psychotherapy: Theory, Research and Practice, 75, 131-150.

Solomon, L. J., \& Rothblum, E. D. (1984). Academic procrastination: Frequency and cognitivebehavioral correlates. Journal of Counseling Psychology, 31, 503-509.

Steel, P. (2007). The nature of procrastination: A meta-analytic and theoretical review of quintessential self regulatory failure. Psychological Bulletin, 133, 65-94.

Taylor, G.J., \& Taylor, H.S. (1997). Alexithymia. In M. McCallum \& W.E. Piper (Eds.), Psychological mindedness: A contemporary understanding (pp. 77-104). Munich: Lawrence Erlbaum Associates.

Tolar, A., \& Reznikoff, M. (1960). A new approach to insight: A preliminary report. The Journal of Nervous and Mental Disease, 130, 286-296.

How to cite this article: Pathak P, Joshi S (2017), Psychological Mindedness and Procrastination among University Students, International Journal of Indian Psychology, Volume 4, Issue 2, No. 86, ISSN:2348-5396 (e), ISSN:2349-3429 (p), DIP:18.01.021/20170402, ISBN:978-1-365-68609-2 